\title{
Metallurgy of the Monitor
}

\author{
Eric Nordgren, ${ }^{*}$ Erin Secord * \\ *The Mariners' Museum, 100 Museum Drive, Newport News, Virginia 23606
}

Archaeological conservators at The Mariners' Museum are working to preserve over 200 tons of metal artifacts and large components recovered by the National Oceanic and Atmospheric Administration (NOAA) from the wreck of the historic Civil War ironclad USS Monitor that sank in 1862. As part of the conservation process, compositional analysis using a scanning electron microscope with energy dispersive spectroscopy (SEM-EDS) and metallography have been used to better understand the alloys and working techniques used in the construction of Monitor and its artifacts.

A thin-walled bucket was excavated from Monitor's gun turret in 2002 and was excessively marine-encrusted compared to other artifacts from the same burial conditions. The volume of concretion masks the thin original material, making identification and characterization of the metal a challenge. George Vander Voort of Buehler Ltd. was successful at mounting and polishing a sample of the fragile cross section. SEM-EDS analysis at the William \& Mary Applied Research Center at Jefferson Laboratory showed that the bucket was constructed of an iron alloy and tin. (Fig.1) The bulk of this tinplate is comprised of the iron alloy with only very thin layers of tin. Corrosion in marine environments has delaminated the tinplate, leaving it weak and brittle.

Very small components from the movement of Monitor's engine room clock were examined to better understand their corrosion processes. The clock's index, which allowed for calibration, initially appeared to be iron. However, it exhibited very little corrosion even though it was in galvanic contact with brass components. SEM-EDS analysis (Fig. 2) showed the index is composed of a copper-nickel alloy with as much as 10 weight percent nickel, hence its excellent preservation.

Future compositional analyses will focus on Monitor's propeller shaft, cast iron components and copper alloys objects. Samples are currently being mounted and polished for metallographic examination. Determination of the composition of Monitor artifacts is necessary for conservators to choose appropriate conservation treatments.

Thanks to Buehler Ltd. and The College of William and Mary for their assistance in this work. 


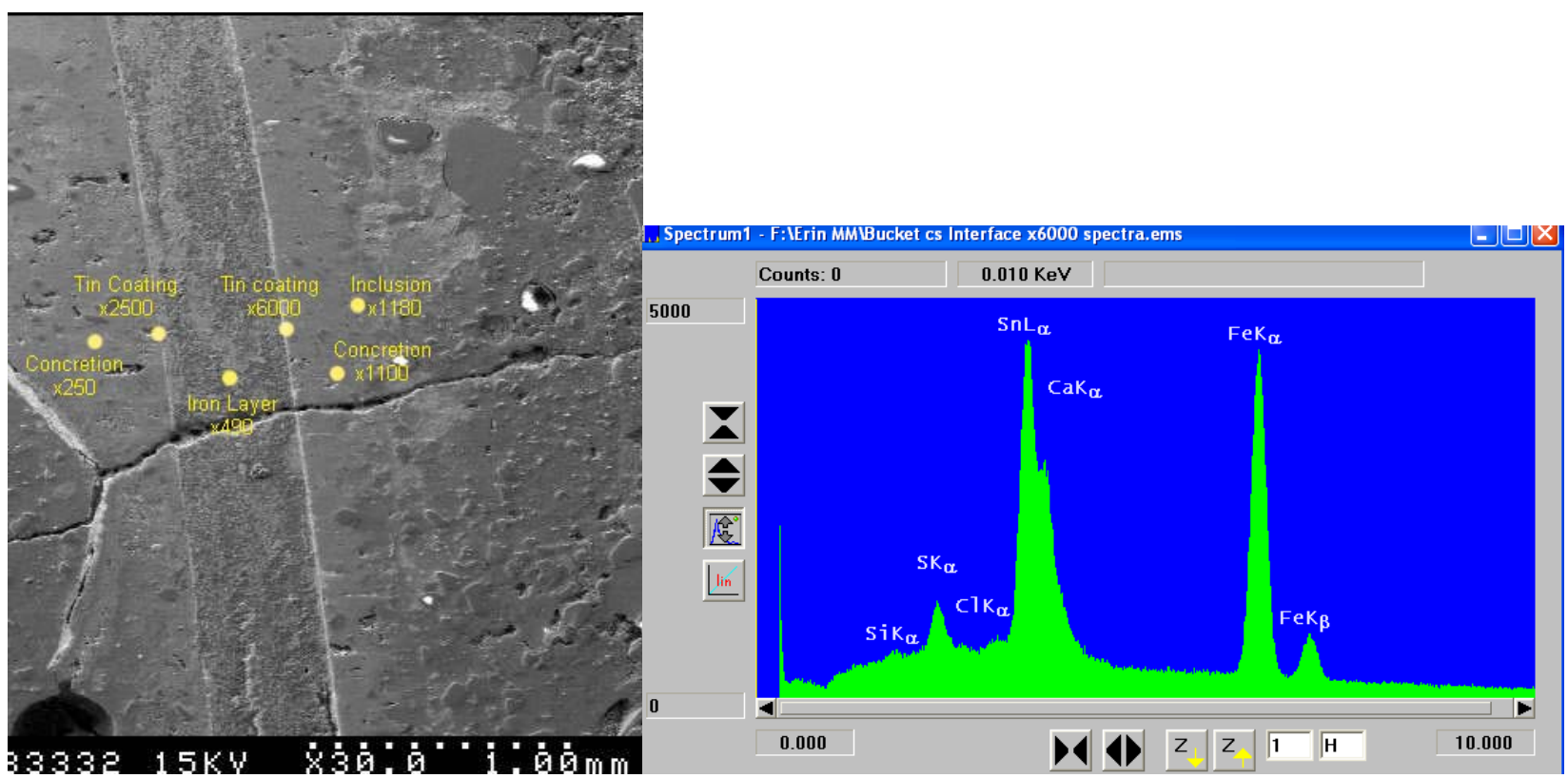

Fig. 1. SEM photo and EDS analysis of thin-walled bucket from Monitor's turret (The Mariners' Museum and The College of William and Mary).

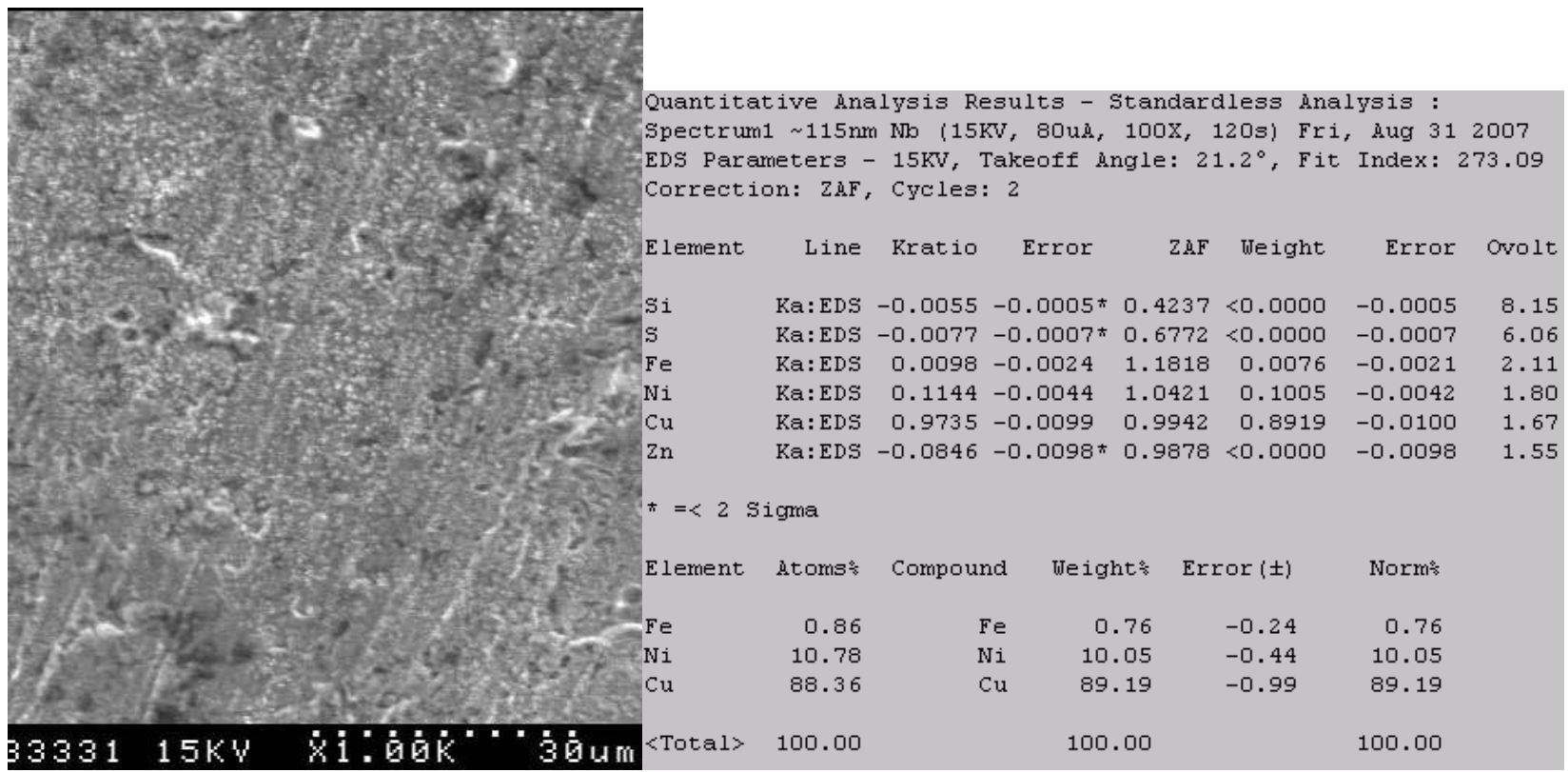

Fig. 2. SEM photo and semi-quantitative EDS analysis of the Index (speed control) from Monitor's engine room clock (The Mariners' Museum and the College of William and Mary). 